\title{
Mechanism of ambient particulate matter and respiratory infections
}

\author{
Luis G. Vargas Buonfiglio, Alejandro P. Comellas \\ Department of Internal Medicine, University of Iowa, Carver College of Medicine, Iowa City, IA, USA \\ Correspondence to: Dr. Alejandro P. Comellas. Department of Internal Medicine, University of Iowa, 200 Hawkins Dr., W219-B GH, Iowa City, IA \\ 52242, USA. Email: alejandro-comellas@uiowa.edu. \\ Provenance and Peer Review: This article was commissioned by the Editorial Office, fournal of Thoracic Disease. The article did not undergo external \\ peer review. \\ Comment on: Liu J, Chen X, Dou M, et al. Particulate matter disrupts airway epithelial barrier via oxidative stress to promote Pseudomonas aeruginosa \\ infection. J Thorac Dis 2019;11:2617-27.
}

Submitted Dec 02, 2019. Accepted for publication Dec 23, 2019.

doi: $10.21037 /$ jtd.2019.12.33

View this article at: http://dx.doi.org/10.21037/jtd.2019.12.33

Air pollution is an important risk factor for respiratory infections. One of the main components of air pollution is particulate matter $(\mathrm{PM})$, a mixture of solid particles and liquid droplets suspended in the air. Acute respiratory infections are one of the leading causes of death worldwide, therefore, it is critical to understand the mechanism by which PM increases the risk of infections (1).

\section{PM air pollution increases the risk of respiratory infections}

There are several proposed mechanisms by which PM can increase respiratory infections. First PM can serve as a carrier of bacteria (2). Once PM arrives into the airway lands on the airway surface liquid and can quickly adsorb and impair peptides and proteins responsible for the airway antimicrobial activity $(3,4)$. Also, PM can decrease mucociliary transport (5), and dampen the expression of antimicrobial peptides such as defensins $(6,7)$. Alveolar macrophages are also responsible for the clearance of particles. PM can inhibit the phagocytic ability of macrophages against pathogenic bacteria such as Pneumococcus pneumoniae (8). Furthermore, our group and Liu et al. observed that PM promotes bacterial growth of airway pathogens. One mechanism might involve iron in PM, serving as an important nutrient for bacterial growth $(4,9)$.

\section{Lung injury by disruption of the epithelial barriers by PM}

$\mathrm{PM}$ is noxious to the lung causing acute lung injury by mechanisms independent of infection. For example, epidemiologic data showed that high PM exposure increased the risk of culture negative pneumonia (10). Potential mechanisms include: (I) PM is directly cytotoxic; (II) PM increases the number of airway inflammatory cells; (III) and PM increases airway inflammatory markers. Also, it has been proposed that endotoxin and transition metal are implicated in this process $(11,12)$. However, one of the central hypothesis in PM induced lung injury is the production of reactive oxygen species (ROS) which result in oxidative stress and cell/tissue damage. The mechanisms by which PM causes oxidative stress are not completely understood but evidence support that generation of free radicals might come from the particle surface, release of transition metals from the particle such as iron that catalyzes Fenton-type reactions and generate hydroxyl radicals, and activation of inflammatory cells (13).

The airway and alveolar epithelial barriers are crucial for a healthy non-injured lung. An intact epithelial barrier prevents airborne pathogens from reaching the bloodstream and cause systemic damage. The barrier consists mainly of tight junctions (TJs), and adherens junctions ( $\mathrm{AJs}$ ). TJs are closer to the apical side and regulate paracellular transport of ions and other molecules, and AJs initiate and 
maintain cell-cell adhesion. (14). PM can also disrupt the airway epithelial barrier by affecting both TJs and AJs. Our group and others demonstrated that PM-induced ROS disrupted TJs by internalization of occludin from the plasma membrane into endosomal compartments and dissociation from Zonula Occludens $1(15,16)$. PM also affected TJ protein claudin 1 but not claudin 5 in bronchial epithelial cells $(9,17)$. AJs are also affected by PM. Exposure of PM to bronchial epithelium caused lysosomal membrane permeabilization, oxidative stress, and lipid peroxidation. Epithelial cells underwent mesenchymal transition, including loss of cell morphology, and decreased E-cadherin expression (18).

PM impairs other mechanisms of epithelial integrity. For example, PM exposure decreased membrane septin-2 and cortical actin. Septin-2-actin interactions and actin rearrangement are required to reinforce the barrier in response to noxious stimuli, therefore, increasing paracellular permeability (19).

\section{PM and invasive disease}

Liu et al. elegantly demonstrated in an in vivo mouse model that PM can increase lung injury, bacterial lung burden, and consequently lead to Pseudomonas bacteremia in a concentration dependent manner (9). Other studies may confirm these finding in humans. In a time-stratified, casecrossover analyses of patients presenting to an emergency department with pneumonia, short term PM exposure was positively correlated with severe pneumonia, intensive care unit admissions, and inpatient mortality (20). Other studies have shown that sulfur dioxide $\left(\mathrm{SO}_{2}\right)$, a component of air pollution, was related to increased risk of invasive pneumococcal disease $(21,22)$. In contrast, another study did not find an association between 30-day PM exposure levels and sepsis (23). However, they consider sepsis from all sources and not only the ones related to the lung infection. Furthermore, as PM has been shown to increase oxidative stress, Liu et al. used the antioxidant $\mathrm{N}$-acetylcysteine (NAC) to reduce epithelial barrier disruption.

In conclusion, we consider that air pollution is a preventable cause of lung injury, respiratory infection, and probably increased the risk of bacteremia via increased bacterial growth and disruption of the airway epithelial barrier. Further studies in humans are required to confirm this association and explore the role of NAC to treat PMinduced lung injury.

\section{Acknowledgments}

Funding: None.

\section{Footnote}

Conflicts of Interest: The authors have no conflicts of interest to declare.

Ethical Statement: The authors are accountable for all aspects of the work in ensuring that questions related to the accuracy or integrity of any part of the work are appropriately investigated and resolved.

Open Access Statement: This is an Open Access article distributed in accordance with the Creative Commons Attribution-NonCommercial-NoDerivs 4.0 International License (CC BY-NC-ND 4.0), which permits the noncommercial replication and distribution of the article with the strict proviso that no changes or edits are made and the original work is properly cited (including links to both the formal publication through the relevant DOI and the license). See: https://creativecommons.org/licenses/by-nc-nd/4.0/.

\section{References}

1. Troeger C, Blacker B, Khalil IA, et al. Estimates of the global, regional, and national morbidity, mortality, and aetiologies of lower respiratory infections in 195 countries, 1990-2016: a systematic analysis for the Global Burden of Disease Study 2016. Lancet Infect Dis 2018;18:1191-210.

2. Liu $\mathrm{H}$, Zhang $\mathrm{X}$, Zhang $\mathrm{H}$, et al. Effect of air pollution on the total bacteria and pathogenic bacteria in different sizes of particulate matter. Environ Pollut 2018;233:483-93.

3. Vargas Buonfiglio LG, Mudunkotuwa IA, Abou Alaiwa MH, et al. Effects of Coal Fly Ash Particulate Matter on the Antimicrobial Activity of Airway Surface Liquid. Environ Health Perspect 2017;125:077003.

4. Borcherding JA, Chen H, Caraballo JC, et al. Coal fly ash impairs airway antimicrobial peptides and increases bacterial growth. PloS One 2013;8:e57673.

5. Cavalcante de Sa M, Nakagawa NK, Saldiva de Andre CD, et al. Aerobic exercise in polluted urban environments: effects on airway defense mechanisms in young healthy amateur runners. J Breath Res 2016;10:046018.

6. Piyadasa H, Hemshekhar M, Carlsten C, et al. Inhaled Diesel Exhaust Decreases the Antimicrobial Peptides alpha-Defensin and S100A7 in Human Bronchial 
Secretions. Am J Respir Crit Care Med 2018;197:1358-61.

7. Chen X, Liu J, Zhou J, et al. Urban particulate matter (PM) suppresses airway antibacterial defence. Respir Res 2018;19:5.

8. Zhou H, Kobzik L. Effect of concentrated ambient particles on macrophage phagocytosis and killing of Streptococcus pneumoniae. Am J Respir Cell Mol Biol 2007;36:460-5.

9. Liu J, Chen X, Dou M, et al. Particulate matter disrupts airway epithelial barrier via oxidative stress to promote Pseudomonas aeruginosa infection. J Thorac Dis 2019;11:2617-27.

10. Croft DP, Zhang W, Lin S, et al. The Association between Respiratory Infection and Air Pollution in the Setting of Air Quality Policy and Economic Change. Ann Am Thorac Soc 2019;16:321-30.

11. Osornio-Vargas Alvaro R, Bonner James C, AlfaroMoreno E, et al. Proinflammatory and cytotoxic effects of Mexico City air pollution particulate matter in vitro are dependent on particle size and composition. Environ Health Perspect 2003;111:1289-93.

12. Ghio AJ, Kim C, Devlin RB. Concentrated Ambient Air Particles Induce Mild Pulmonary Inflammation in Healthy Human Volunteers. Am J Respir Crit Care Med 2000;162:981-8.

13. Alvarez S, Evelson PA. Nitric oxide and oxygen metabolism in inflammatory conditions: sepsis and exposition to polluted ambients. Front Biosci 2007;12:964-74.

14. Rezaee F, Georas SN. Breaking barriers. New insights into airway epithelial barrier function in health and disease. Am J Respir Cell Mol Biol 2014;50:857-69.

15. Caraballo JC, Yshii C, Westphal W, et al. Ambient particulate matter affects occludin distribution and

Cite this article as: Vargas Buonfiglio LG, Comellas AP. Mechanism of ambient particulate matter and respiratory infections. J Thorac Dis 2020;12(3):134-136. doi: 10.21037/ jtd.2019.12.33 increases alveolar transepithelial electrical conductance. Respirology 2011;16:340-9.

16. Lehmann AD, Blank F, Baum O, et al. Diesel exhaust particles modulate the tight junction protein occludin in lung cells in vitro. Part Fibre Toxicol 2009;6:26.

17. Kim SS, Kim CH, Kim JW, et al. Airborne particulate matter increases MUC5AC expression by downregulating Claudin-1 expression in human airway cells. BMB Rep 2017;50:516-21.

18. Thevenot PT, Saravia J, Jin N, et al. Radical-containing ultrafine particulate matter initiates epithelial-tomesenchymal transitions in airway epithelial cells. Am J Respir Cell Mol Biol 2013;48:188-97.

19. Sidhaye VK, Chau E, Breysse PN, et al. Septin-2 mediates airway epithelial barrier function in physiologic and pathologic conditions. Am J Respir Cell Mol Biol 2011;45:120-6.

20. Pirozzi CS, Jones BE, VanDerslice JA, et al. Short-Term Air Pollution and Incident Pneumonia. A Case-Crossover Study. Ann Am Thorac Soc 2018;15:449-59.

21. Kim PE, Musher DM, Glezen WP, et al. Association of invasive pneumococcal disease with season, atmospheric conditions, air pollution, and the isolation of respiratory viruses. Clin Infect Dis 1996;22:100-6.

22. Sahuquillo-Arce JM, Ibáñez-Martínez E, HernándezCabezas A, et al. Influence of environmental conditions and pollution on the incidence of Streptococcus pneumoniae infections. ERJ Open Res 2017. doi: 10.1183/23120541.00014-2017.

23. Sarmiento EJ, Moore JX, McClure LA, et al. Fine Particulate Matter Pollution and Risk of CommunityAcquired Sepsis. Int J Environ Res Public Health 2018;15. pii: E818. 